\title{
ESTUDO DA USABILIDADE DE COMANDOS DE UM
} MOTOCULTIVADOR AGRÍCOLA

\section{USABILITY STUDY OF AGRICULTURAL POWER TILLER}

\author{
Ricardo Kozoroski Veiga (1), Leila Amaral Gontijo (2), Fabrício Campos \\ Masiero(3), Willian Odorizzi(4), Juclei Venturi(5) \\ (1)Doutorando, Universidade Federal de Santa Catarina -UFSC \\ e-mail: ricardoveiga@ifc-riodosul.edu.br \\ (2)Doutora, Universidade Federal de Santa Catarina -UFSC \\ e-mail:leila@deps.ufsc.br \\ (3)Doutor, Instituto Federal Catarinense-IFC \\ e-mail:masiero@ifc-riodosul.edu.br \\ (4)Graduando, Instituto Federal Catarinense-IFC \\ e-mail:odorizzi_w@hotmail.com \\ (5)Graduando, Instituto Federal Catarinense-IFC \\ e-mail:jucleixd@hotmail.com
}

\begin{abstract}
RESUMO
Santa Catarina, pelas características geográficas, apresentou o desenvolvimento da agricultura familiar em pequenas glebas. O reduzido tamanho das propriedades rurais demandou a utilização de máquinas de pequeno porte, como o motocultivador. Estima-se que neste estado existam mais de 24 mil destas máquinas. Buscando avaliar o grau de usabilidade de um motocultivador, o estudo utilizou os métodos de análise Usa- Design e o teste de usabilidade. A amostragem foi de 53 voluntários, a maioria do meio rural. O resultado encontrado evidenciou deficiências ergonômicas e necessidade de melhoria em 7 dos 10 princípios da usabilidade adotados.
\end{abstract}

Palavras-chave: Comandos, motocultivador, usabilidade

\begin{abstract}
Santa Catarina present the development of family farming in small plots. The small size of farms required the use of small machines, such as the power tillers. It is estimated that this state there are more than 24 thousand of these machines. Trying to evaluate the degree of usability of a power tiller, the study used the USA-Design method and usability testing. The sample was 53 volunteers, most of the rural areas. The results found showed ergonomic deficiencies and need for improvement in 7 of the 10 principles of usability adopted.
\end{abstract}

Keywords: Controls, power tiller, usability 


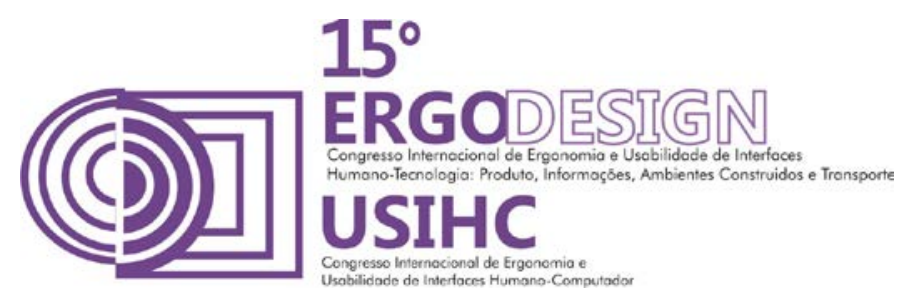

A mecanização da agricultura brasileira propiciou um incremento na produção e maior eficiência das operações agrícolas, mas também trouxe consequências negativas como doenças ocupacionais e acidentes. As máquinas que viabilizaram a agricultura em pequenas parcelas, como na agricultura familiar catarinense, foram os microtratores e motocultivadores. Estas, juntamente com os tratores, são as máquinas que oferecem os maiores riscos à saúde e vida dos agricultores.

Estima-se que Santa Catarina possua mais de 24 mil motocultivadores e microtratores em operação (IBGE, 2007). A maior concentração está na região do Alto Vale do Itajaí. Estas máquinas são categorizadas pela potência, que na maioria dos casos é inferior à 20 cavalos-vapor (cv).

Embora de pequena dimensão e peso, acidentes com estas máquinas são frequentes e podem ocasionar grandes de lesões aos operadores. Odorizzi et al., (2013) após investigarem 110 acidentes ocorridos com máquinas agrícolas em Santa Catarina, identificou que $26 \%$ do total ocorre com motocultivadores, neste estudo caracterizados por potência inferior à $15 \mathrm{cv}$.

Veiga et al. (2014c) salientam que o motocultivador foi concebido para trabalho na posição em pé e que atualmente a maiora das operações agrícolas são realizadas na posição sentada e isso impõe severas limitações ergonômicas, entre elas estão as distâncias dos comandos da máquina, que excedem os valores ergonômicos.

Venturi et al. (2014) em estudo sobre a distribuição de ruído nas proximidades de máquinas agrícolas apontam nível de ruído de $95 \mathrm{~dB}$ no posto de trabalho do operador. Nesta condição a exposição diária permissível, sem EPI, seria de 2 horas. A distância segura para uma jornada de 8 horas nas proximidades do motocultivador foi de 3,8 metros. O agravante, nesse tipo de máquina, é sua utilização - mesmo sendo proibida por lei - para o transporte de pessoas que ficam sobre a carreta a aproximadamente 2 metros da fonte de máximo ruído.

Assim o estudo da interação homem-máquina pode contribuir para conhecer as limitações da máquina, seus pontos fortes e fracos e se alguma dessas deficiências pode levar à erros de operação e/ou acidentes. Uma das maneiras de explorar essa interação é através do estudo da usabilidade, onde o produto é avaliado em seu contexto de uso.

Este trabalho propõe a avaliação do motocultivador, no que se refere à sua usabilidade, empregando o modelo Usa-Design (U-DC) (MERINO et al., 2012).

\section{PROCEDIMENTOS METODOLÓGICOS}

\subsection{Caracterização da Pesquisa}

A avaliação da usabilidade do produto seguiu os princípios de Jordan (1998) e a ISO 924111 (1998), que são a base do modelo Usa-Design (U-DC) (MERINO et al., 2012).

Seguindo a classificação de Vieira (2008) para natureza e abordagem e Gil (1991) para objetivos e procedimentos, a pesquisa enquadra-se como:

Quadro 1. Classificação da pesquisa

\begin{tabular}{|l|l|}
\hline Natureza & Pesquisa Aplicada \\
\hline Abordagem do problema & Pesquisa Qualitativa e Quantitativa \\
\hline Objetivos & Pesquisa Explicativa \\
\hline Procedimentos técnicos & $\begin{array}{l}\text { Bibliográfica, experimental e } \\
\text { levantamento }\end{array}$ \\
\hline
\end{tabular}




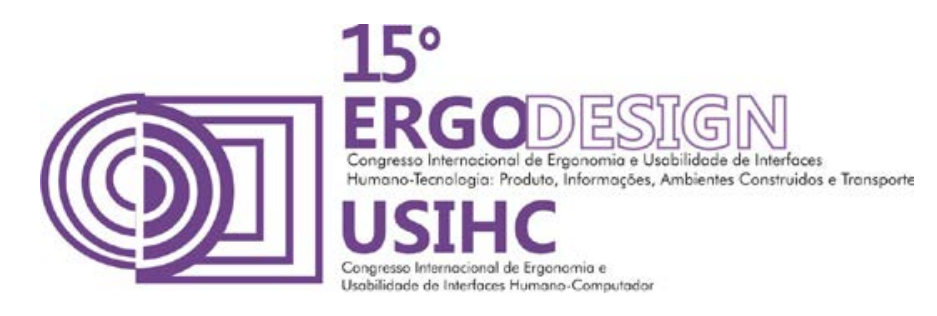

\subsection{Teste de Usabilidade - Questionário}

Foi conduzido em instituição de ensino técnico e superior federal e contou com amostra de 53 estudantes, sendo 13 do sexo feminino e 40 do masculino, com faixa etária entre 15 e 20 anos. Destes, 33 pertenciam à agricultura familiar catarinense.

O teste avaliou a usabilidade da seguinte máquina agrícola: motocultivador modelo Kubota Tobatta, ano 1995, de 16 cv de potência.

Cada indivíduo respondeu o seguinte questionário:

Quadro 1: Questionário aplicado aos usuários

\begin{tabular}{|c|c|c|}
\hline Ordem & Questão & Alternativas \\
\hline 1 & Idade? & - \\
\hline 2 & Já sofreu acidente com a máquina? & $\begin{array}{l}\text { ( ) sim } \\
\text { ( ) não }\end{array}$ \\
\hline 3 & $\begin{array}{l}\text { Em comparação com o trator, o } \\
\text { motocultivador é: }\end{array}$ & $\begin{array}{l}\text { ( ) mais seguro } \\
\text { ( ) menos seguro } \\
\text { ( ) indiferente }\end{array}$ \\
\hline 4 & Possui motocultivador na família? & 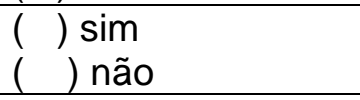 \\
\hline 5 & $\begin{array}{c}\text { Quantos anos de experiência com a } \\
\text { máquina? }\end{array}$ & $\begin{array}{l}\text { ( ) nenhuma } \\
\text { ( ) menos de } 1 \text { ano } \\
\text { ( ) mais de } 1 \text { ano }\end{array}$ \\
\hline
\end{tabular}

\subsection{Teste de Usabilidade - Modelo Usa-Design}

No processo de avaliação da usabilidade empregou-se o modelo Usa-Design (UDC) (MERINO et al., 2012) que utiliza a estrutura apresentada na figura a seguir.

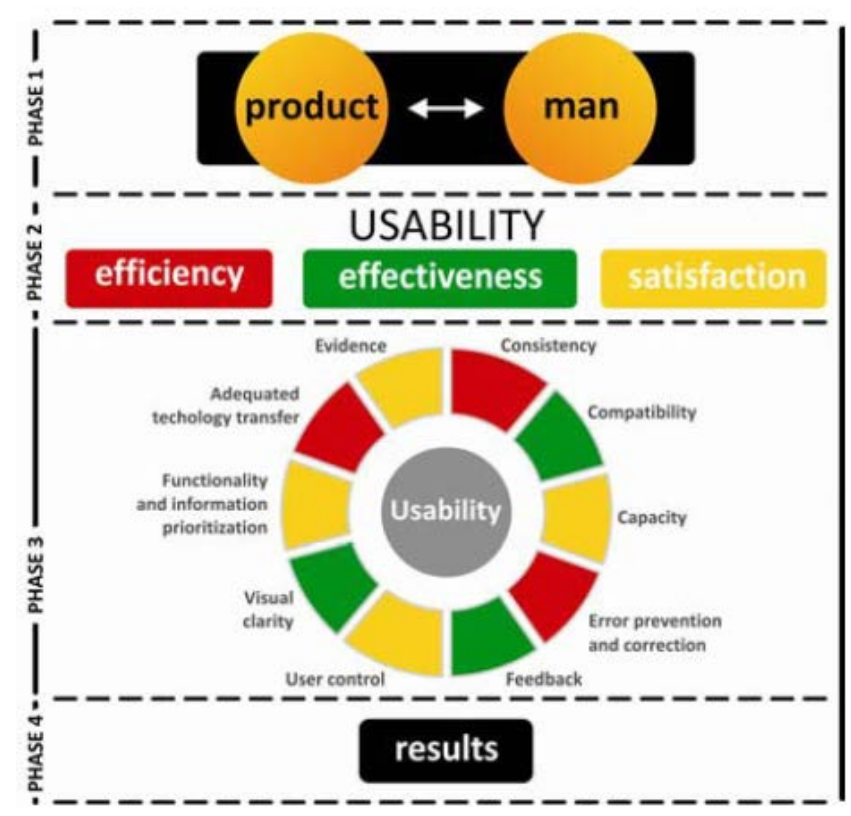

Figura 1: Modelo Usa-Design

Fonte: Merino et al., (2012) 


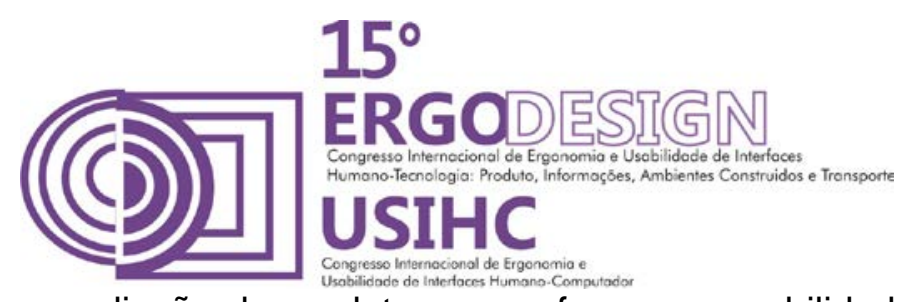

O método consiste na avaliação do produto com enfoque na usabilidade, onde na fase I é avaliado o contexto de uso do produto, podendo ser utilizadas técnicas como análise funcional, análise morfológica entre outros. Na fase II são avaliadas a eficiência, eficácia e satisfação do usuário à respeito do produto. O resultado desta fase é representado por uma escala de cores, onde o vermelho representa "não atende", o amarelo "atende parcialmente" e o verde "atende". Uma escala numérica suporta a avaliação, conforme figura à seguir:

\begin{tabular}{|c|c|c|c|c|}
\hline & $\begin{array}{l}\text { does not } \\
\text { attend }\end{array}$ & $\begin{array}{l}\text { partially } \\
\text { attends }\end{array}$ & $\begin{array}{l}\text { partially } \\
\text { attends }\end{array}$ \\
\hline \multirow{3}{*}{ 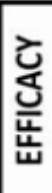 } & $\begin{array}{c}\text { Percentage of } \\
\text { targets achieved }\end{array}$ & $0-59 \%$ & $60-89 \%$ & $90-100 \%$ \\
\hline & $\begin{array}{c}\text { Percentage of } \\
\text { users completing } \\
\text { the task with sucess }\end{array}$ & $0-59 \%$ & $60-89 \%$ & $90-100 \%$ \\
\hline & $\begin{array}{l}\text { Average accuracy } \\
\text { of completed tasks }\end{array}$ & $0-59 \%$ & $60-89 \%$ & $90-100 \%$ \\
\hline \multirow{3}{*}{ 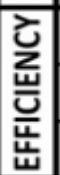 } & $\begin{array}{c}\text { Time to } \\
\text { complete a task }\end{array}$ & $0-59 \%$ & $60-89 \%$ & $90-100 \%$ \\
\hline & $\begin{array}{l}\text { Tasks completed } \\
\text { per unit of time }\end{array}$ & - & - & - \\
\hline & $\begin{array}{c}\text { Financial cost to } \\
\text { accomplish the task }\end{array}$ & $0-59 \%$ & $60-89 \%$ & $90-100 \%$ \\
\hline \multirow{3}{*}{ 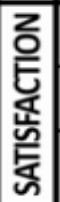 } & Satisfaction scale & $0-59 \%$ & $60-89 \%$ & $90-100 \%$ \\
\hline & Use frequency & $0-59 \%$ & $60-89 \%$ & $90-100 \%$ \\
\hline & $\begin{array}{l}\text { Complaints } \\
\text { frequency }\end{array}$ & $100-70 \%$ & $69-11 \%$ & $10-0 \%$ \\
\hline
\end{tabular}

Figura 2: Fase II do Modelo Usa-Design Fonte: Merino et al., (2012)

Na fase III a estrutura de medição se utiliza de uma escala cromática (qualitativa) e também numérica (quantitativa) baseada nos dez princípios da usabilidade de Jordan (1998), conforme figura a seguir:

\begin{tabular}{|c|c|c|c|}
\cline { 2 - 4 } \multicolumn{1}{c|}{} & \multicolumn{3}{c|}{ MEASUREMENT } \\
\hline QUANTITATIVE & 1 & 2 & 3 \\
\hline QUALITATIVE & & & \\
\hline READING & $\begin{array}{c}\text { does not } \\
\text { attend }\end{array}$ & $\begin{array}{c}\text { partially } \\
\text { attends }\end{array}$ & $\begin{array}{c}\text { completely } \\
\text { attends }\end{array}$ \\
\hline
\end{tabular}

Figura 3: Estrutura de medição da fase III Fonte: Merino et al., (2012)

Os resultados da avaliação global são apresentados de forma descritiva na fase IV deste modelo.

\section{FUNDAMENTAÇÃO TEÓRICA}

\subsection{Motocultivadores}

A maioria dos motocultivadores utilizam motores monocilíndricos refrigerados a ar. Normalmente são empregados motores à diesel de quatro tempos com potência entre $10 \mathrm{e}$ 


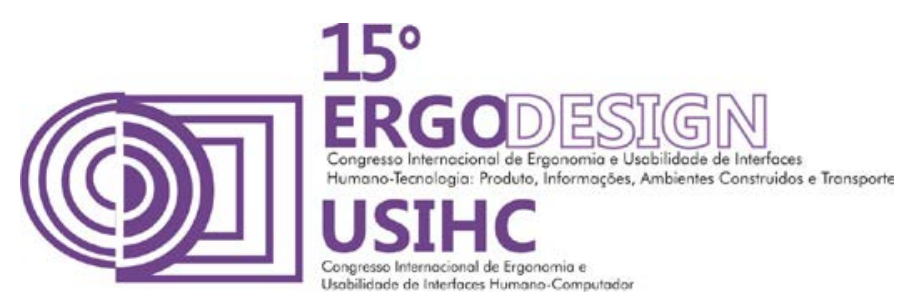

20 Cv. A cilindrada varia entre 250 e 500 centímetros cúbicos com um regime de funcionamento máximo de 3800 rotações por minuto (MÁRQUEZ, 2011).

Por possuírem apenas um eixo e duas rodas, não se classificam como tratores, tampouco como microtratores, como popularmente são chamados. Segundo Bray (1986), as dimensões reduzidas e o baixo peso do motocultivador permitem seu deslocamento em terrenos alagados, como plantações de arroz irrigado, e a realização de manobras em pequenas parcelas cultivadas. A condição de trabalho do operador inclui todos os fatores do ambiente, que têm um efeito sobre o sistema homem-máquina. Entre esses fatores a vibração mecânica e o ruído são os mais importantes, pois aceleram a fadiga e afetam a sensibilidade de reação do operador. A figura a seguir apresenta a configuração do motocultivador com adaptação da carreta, usada para transporte de carga e pessoas.

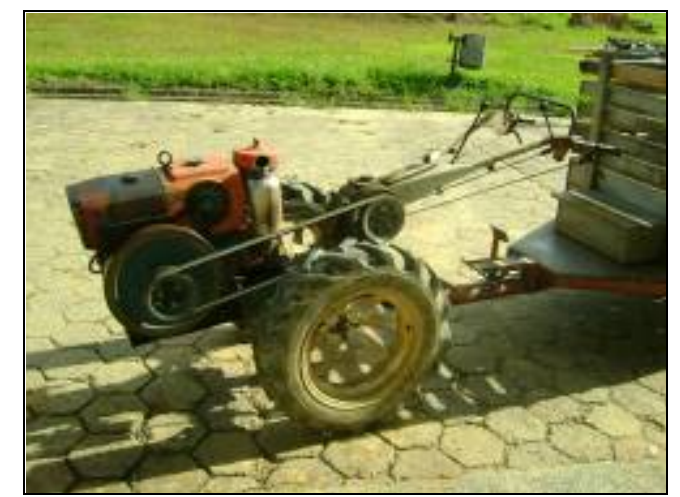

Figura 4. Motocultivador com adaptação para a posição sentada. Fonte: Veiga et al. (2014b)

Tanto na configuração para operação em pé como sentado, o sistema de direcionamento é por embreagem em cada roda de tração, ou seja, aciona-se a embreagem de uma roda e a outra traciona direcionando a máquina. O resultado do acionamento (o sentido que o motocultivador irá tomar) depende do relevo, se em aclive ou declive.

Sam e Kathirvel (2009) afirmam que existe um grande número de pequenas propriedades na Índia e por isso o motocultivador é bastante empregado, sendo equipamento mais adequado tendo-se em conta o seu tamanho compacto e versatilidade. Para esses autores o uso contínuo do motocultivador pode envolver o risco de doenças vasculares das mãos, mesmo após períodos relativamente curtos, em condições normais de trabalho e os resultados sugerem que é necessário para reduzir a vibração transmitida para as mãos do usuário, fornecendo sistemas de isolamento adequados.

Para Mitarai et al.(2008), em estudo realizado nas Filipinas com 124 operadores de motocultivadores, dentre os principais problemas mencionados pelos operadores de motocultivadores estão o excessivo ruído do motor, grande esforço na partida do motor e mau dimensionamento dos comandos da máquina. Os resultados destacaram a importância de se realizarem estudos visando a melhoria dos motocultivadores.

Em estudo na região do Alto Vale de Santa Catarina, Veiga et al. (2014a) destacam que o motocultivador não é a melhor alternativa para terrenos acidentados com exigências de manobras constantes. Além disso apontam a necessidade de melhoria do posto de trabalho na condução do motocultivador. As distâncias inadequadas entre comandos e os esforços necessários para a condução também foram mencionadas pelos autores. 


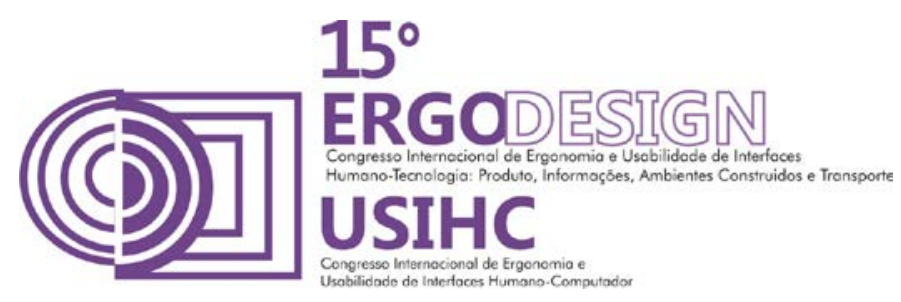

\subsection{Usabilidade}

Um dos aspectos mais relevantes na escolha de um produto pelo cliente é a capacidade de se adaptar ao uso deste e o quanto o produto atende à sua demanda técnica, ou seja, se realiza o que o usuário imagina que pode alcançar com esse objeto ou serviço.

Conforme ISO 9241-11 (1998), a usabilidade é definida como a capacidade de um produto ser usado por usuários específicos para atingir objetivos específicos com eficácia, eficiência e satisfação em um contexto específico de uso. Jordan (1998) define esses três parâmetros da seguinte forma:

- Eficácia: refere-se à extensão na qual uma meta é alcançada ou uma tarefa é realizada;

- Eficiência: refere-se à quantidade de esforço necessário para se atingir a meta. Quanto menor for o esforço, maior será a eficiência;

- Satisfação: refere-se ao nível de conforto que os usuários percebem quando utilizam o produto, ou seja, a aceitação pelos usuários para atingir as suas metas.

Também a ISO 9241-11 (1998) define a usabilidade não somente como propriedade intrínseca do produto isoladamente, mas dependente do contexto específico de uso, ou seja, quem está utilizando o produto, para qual finalidade e o tipo específico de ambiente.

A usabilidade é, portanto, uma propriedade da interação entre produto, usuário e a tarefa que este usuário está realizando.

Os princípios para o design com usabilidade proposto por Jordan (1998) são explicados a seguir:

1. Coerência: Projetar com coerência significa que características similares devem ser realizadas da mesma maneira. Como um usuário ganha experiência com o produto, ele pode aplicar esse conhecimento para ajudar a alcançar os objetivos de outra. Incoerências podem levar a erros.

2. Compatibilidade: A compatibilidade deve assegurar que a maneira que um produto funciona atende às expectativas do usuário, baseada no conhecimento que ele tem do mundo ao seu redor. A compatibilidade se difere da coerência, uma vez que a coerência se refere a regularidades no design dentro de produtos similares. Já a compatibilidade se refere às regularidades do design entre um produto e as fontes externas.

3. Capacidade: Ao interagir com um produto um usuário pode usar uma variedade de suas habilidades ou "canais". É importante que quando se usa um produto, nenhuma das habilidades do usuário seja sobrecarregada, porque se isso ocorrer tem-se um problema de usabilidade.

4. Retroalimentação: É importante que o produto, por suas interfaces, ofereçam reações claras sobre as ações realizadas pelo usuário. A falta de uma indicação significativa sobre os resultados dessas ações pode fazer com que o usuário repita a operação ou se sinta perdido.

5. Prevenção de erro e recuperação: Parece inevitável que usuários cometam erros de tempo em tempo quando usam um produto. No entanto, os produtos podem ser projetados com a possibilidade de minimizar a ocorrência de erros e o usuário recuperar, de forma rápida erro que tenha cometido. 


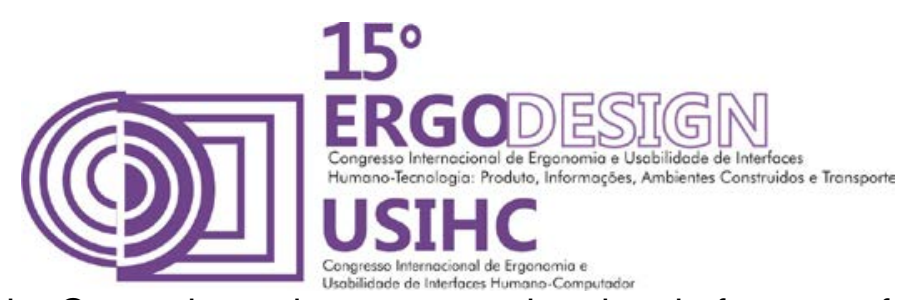

6. Controle do usuário: Os produtos devem ser projetados de forma a oferecer o máximo de controle aos usuários sobre as interações, ou seja, sobre as ações tomadas no produto.

7. Clareza visual: É importante que a informação seja apresentada de forma que ela possa ser lida rápida e facilmente sem causar qualquer confusão. As informações de feedback incluem-se nesse princípio.

8. Priorização da funcionalidade: Projetar um produto de maneira que a funcionalidade e a informação mais importantes sejam facilmente acessadas pelo usuário.

9. Transferência adequada de tecnologia: Tecnologias que foram desenvolvidas para um propósito sendo aplicadas para outra área podem trazer grandes benefícios para os usuários. No entanto, se feitas sem cuidado suficiente podem também trazer problemas.

10. Evidência: Produtos devem ser projetados de forma que seja claro a forma como operálos. Projetar um produto de maneira que sejam dados indícios de como ele funciona e o método para operá-lo.

No projeto de máquinas e equipamentos agrícolas motorizados os princípios da coerência, compatibilidade, feedback e prevenção de erros merecem especial atenção. Por se tratar de posto de trabalho móvel e envolver uma diversidade de comandos, estas máquinas exigem uma carga mental elevada para sua operação.

\section{ANÁLISE E DISCUSSÃO}

\subsection{Resultados do teste de usabilidade - Questionário}

O resultado do questionário demonstrou que a maioria dos entrevistados estava tendo contato pela primeira vez com o motocultivador, ou seja, 36 dos 53 entrevistados.

Embora a maioria dos entrevistados não tivesse contado anterior, 23 dos 53 jovens possuíam motocultivador em sua propriedade agrícola familiar.

Esses números reforçam a existência da agricultura familiar bem desenvolvida no estado e que o motocultivador está presente em grande parte das propriedades, em número próximo ao de tratores.

A constatação de que apenas $32 \%$ possuíam experiência em motocultivadores e considerando que este estava presente em $43 \%$ das propriedades dos entrevistados pode ser explicado pelo receio dos pais em ensinarem os filhos a operar motocultivadores, pelo risco de acidentes que este oferece.

A percepção do usuário quando questionado quanto à segurança, demonstrou que $98,1 \%$ considerava o motocultivador menos seguro que o trator.

\subsection{Resultados da avaliação de usabilidade}

Na fase I do modelo U-DC a análise global de funcionalidade demonstrou que a máquina apresenta funções básicas de qualquer veículo, que são: acelerador, embreagem, freio e troca de velocidades (câmbio). O maior diferencial entre o motocultivador e demais veículos (carros e tratores) esta no sistema de direção: onde normalmente se encontra o volante (nos veículos) encontra-se rabiças (prolongamento, como um guidão de motocicleta) no motocultivador. 


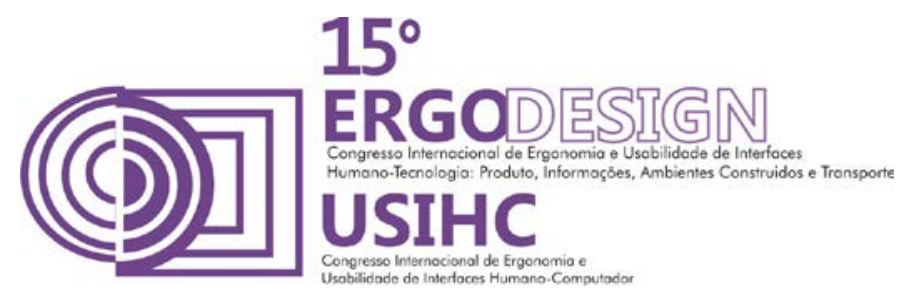

A seguir são apresentados, em quadros, os resultados das avaliações dos princípios cujo status caracterizou-se como "não atendem" pelos parâmetros do modelo proposto:

\subsubsection{Compatibilidade}

Quadro 2: Análise do Princípio da Compatibilidade para o Motocultivador

\begin{tabular}{|c|l|}
\hline Função & \multicolumn{1}{|c|}{ Motocultivador } \\
\hline Acelerador & $\begin{array}{l}\text { O acelerador de mão apresenta compatibilidade pois } \\
\text { aumenta a rotação no sentido horário. }\end{array}$ \\
\hline Embreagem & $\begin{array}{l}\text { A embreagem individual (por roda) é do tipo manete e } \\
\text { contraria estereótipo básico pois o lado de } \\
\text { acionamento depende da declividade, na subida deve- } \\
\text { se acionar um lado, já na descida, outro. } \\
\text { A embreagem geral do tipo alavanca fica entre a } \\
\text { posição "engatado" e "frenado", sendo também de } \\
\text { difícil compreensão. }\end{array}$ \\
\hline Freio & $\begin{array}{l}\text { Tanto a alavanca para freio no eixo do motocultivador } \\
\text { como o da carreta são compatíveis. }\end{array}$ \\
\hline Velocidade & $\begin{array}{l}\text { A caixa de quatro marchas é acionada por alavanca e } \\
\text { apresenta compatibilidade. Já a redução realizada pela } \\
\text { troca de polias é complexa e de difícil compreensão. }\end{array}$ \\
\hline Direção & $\begin{array}{l}\text { A rabiça segue o estereótipo do guidão, porém é } \\
\text { necessário também o acionamento da embreagem } \\
\text { para possibilitar o giro. Assim, para dobrar à direita em } \\
\text { um aclive é necessário debrear a roda direira. Em } \\
\text { declive é necessário debrear a roda esquerda. }\end{array}$ \\
\hline
\end{tabular}

\subsubsection{Capacidade}

Quadro 3: Análise do Princípio da Capacidade para o Motocultivador

\begin{tabular}{|c|l|}
\hline Função & \multicolumn{1}{c|}{ Motocultivador } \\
\hline Acelerador & $\begin{array}{l}\text { O acelerador de mão apresenta-se impreciso e não } \\
\text { mantém a rotação devido à forte vibração no manete. }\end{array}$ \\
\hline Embreagem & $\begin{array}{l}\text { A embreagem individual (para cada roda) exige pega em } \\
\text { pinça desvio ulnar acentuado. Já a embreagem geral } \\
\text { exige que o operador se afaste do encosto do posto de } \\
\text { trabalho. }\end{array}$ \\
\hline Freio & $\begin{array}{l}\text { O freio por alavanca exige que o operador levante do } \\
\text { acento ou fique sem encosto lombar (depende da } \\
\text { estatura do operador) Já o freio da carreta pode ser } \\
\text { acionado da posição sentado e sem grande esforço } \\
\text { físico. }\end{array}$ \\
\hline Troca de & $\begin{array}{l}\text { A caixa marchas exige a flexão do tronco e perda do } \\
\text { apoio lombar. Já a redução realizada pela troca de polias } \\
\text { é complexa e exige grande esforço físico. }\end{array}$ \\
\hline Direção & $\begin{array}{l}\text { A força necessária para fazer uma conversão, em ponto } \\
\text { morto, é de aproximadamente 15 Kgf. }\end{array}$ \\
\hline
\end{tabular}

\subsubsection{Retro-alimentação (feedback)}

Quadro 4: Análise do Princípio da Retroalimentação para o Motocultivador 


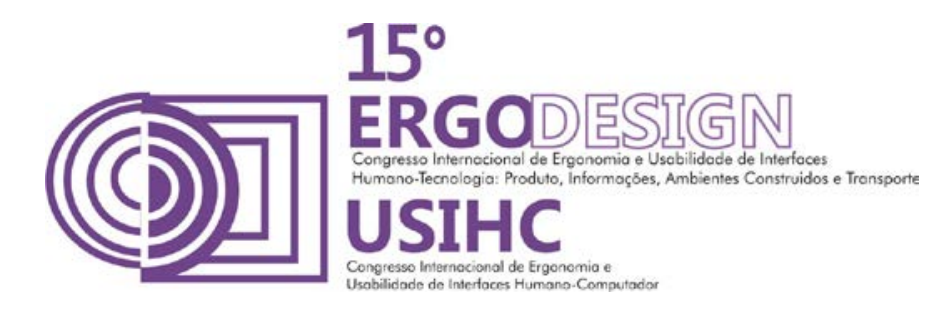

\begin{tabular}{|c|l|}
\hline Função & \multicolumn{1}{c|}{ Motocultivador } \\
\hline Acelerador & $\begin{array}{l}\text { O acelerador de mão não apresenta qualquer feedback } \\
\text { ao operador, não há painel de mostradores e sequer } \\
\text { marcações indicativas na alavanca. }\end{array}$ \\
\hline Embreagem & $\begin{array}{l}\text { Não há retroalimentação senão a reação da máquina ao } \\
\text { comando e a posição final dos elementos (alavanca e } \\
\text { manetes). }\end{array}$ \\
\hline Freio & $\begin{array}{l}\text { Não há retroalimentação senão a reação da máquina ao } \\
\text { comando e a posição final dos elementos (alavanca e } \\
\text { pedal). }\end{array}$ \\
\hline Troca de & $\begin{array}{l}\text { Não há retroalimentação senão a reação da máquina ao } \\
\text { comando e a posição final dos elementos (alavanca e } \\
\text { correia). }\end{array}$ \\
\hline Direção & $\begin{array}{l}\text { Não há retroalimentação senão a reação da máquina ao } \\
\text { comando e a posição final da rabiça. }\end{array}$ \\
\hline
\end{tabular}

\subsubsection{Prevenção de Erros}

Quadro 5: Análise do Princípio da Prevenção de Erros para o Motocultivador

\begin{tabular}{|c|l|}
\hline Função & \multicolumn{1}{c|}{ Motocultivador } \\
\hline Acelerador & $\begin{array}{l}\text { O acelerador de mão não apresenta mola de retorno e } \\
\text { ao se retirar a mão este mantém a última rotação } \\
\text { aplicada, porém de forma muito imprecisa. }\end{array}$ \\
\hline Embreagem & $\begin{array}{l}\text { Não possui sensor que impeça a ignição do motor se } \\
\text { esta estiver com marcha engatada. }\end{array}$ \\
\hline Freio & $\begin{array}{l}\text { Por não possuir assistência mecânica o peso da carga } \\
\text { influi na força necessária para parar o veículo, o que } \\
\text { aumenta o risco de acidentes em casos de desvio de } \\
\text { obstáculos. }\end{array}$ \\
\hline Troca de & $\begin{array}{l}\text { As trocas exigem veículo parado. O arranque com } \\
\text { marcha avançada pode representar risco de perda de } \\
\text { dirigibilidade e até a queda do operador. }\end{array}$ \\
\hline Direção & $\begin{array}{l}\text { Não há nenhum sistema preventivo ou que reduza os } \\
\text { danos em caso de erros. }\end{array}$ \\
\hline
\end{tabular}

\subsubsection{Controle do usuário}

Quadro 6: Análise do Princípio do Controle do Usuário para o Motocultivador

\begin{tabular}{|c|l|}
\hline Função & \multicolumn{1}{c|}{ Motocultivador } \\
\hline Acelerador & $\begin{array}{l}\text { O acelerador de mão está localizado na extremidade da } \\
\text { rabiça, sujeito à vibração e exige que o operador retire a } \\
\text { mão de apoio para sua regulagem. Por isso apresenta- } \\
\text { se impreciso e de difícil controle. }\end{array}$ \\
\hline \multirow{3}{*}{ Embreagem } & $\begin{array}{l}\text { A embreagem por manete apresenta a limitação de ser } \\
\text { acionada pela mão de apoio, assim o operador perde } \\
\text { momentaneamente um importante ponto de equilíbrio. O } \\
\text { mesmo ocorre com a embreagem geral (por alavanca) } \\
\text { com o agravante de exigir que o operador perca o apoio } \\
\text { lombar do acento. }\end{array}$ \\
\hline Freio & O freio no eixo motor exige que o operador flexione a \\
\hline
\end{tabular}




\begin{tabular}{|c|c|}
\hline & $\begin{array}{l}\text { coluna, perdendo o apoio lombar do acento. Já o freio da } \\
\text { carreta é acionado pelo é e difícil de ser acionado } \\
\text { simultaneamente com o freio do eixo motor. A frenagem } \\
\text { isolada da carreta ou do motocultivador pode ocasionar } \\
\text { acidentes por se tratar de estrutura articulada. }\end{array}$ \\
\hline $\begin{array}{l}\text { Troca de } \\
\text { Velocidade }\end{array}$ & $\begin{array}{l}\text { As trocas que exigem a máquina parada representam } \\
\text { perdas na operação e maior risco de acidentes. }\end{array}$ \\
\hline Direção & $\begin{array}{l}\text { Para realizar o máximo esterçamento o operador deve } \\
\text { conduzir o pega-mão com o braço do lado oposto ou até } \\
\text { descer da máquina e conduzi-la em pé. }\end{array}$ \\
\hline
\end{tabular}

4.2.6 Priorização da Funcionalidade

Quadro 7. Análise do Princípio da Funcionalidade para o Motocultivador

\begin{tabular}{|c|c|}
\hline Função & Motocultivador \\
\hline Acelerador & $\begin{array}{l}\text { Não há priorização da informação por não haver } \\
\text { velocímetro ou tacômetro presentes. A função } \\
\text { acelerador exige que o operador retire a mão de apoio } \\
\text { para sua requlagem. }\end{array}$ \\
\hline Embreagem & $\begin{array}{l}\text { A embreagem por manete apresenta a limitação de ser } \\
\text { acionada pela mão de apoio embora esteja em local de } \\
\text { destaque na rabiça da máquina. Já a embreagem geral } \\
\text { (por alavanca) fica afastada e exige que do operador } \\
\text { flexão de tronco e perca o apoio lombar do acento. }\end{array}$ \\
\hline Freio & $\begin{array}{l}\text { O freio no eixo motor exige que o operador flexione a } \\
\text { coluna para localizá-lo e acioná-lo. Já o freio da carreta } \\
\text { é posicionado no campo visual do operador e situado em } \\
\text { distância adequada ao alcance dos pés do operador. }\end{array}$ \\
\hline $\begin{array}{l}\text { Troca de } \\
\text { Velocidade }\end{array}$ & $\begin{array}{l}\text { A alavanca de troca está em região central bem visível, } \\
\text { mas exige a flexão do tronco e perda do apoio lombar. } \\
\text { Já a redução exige o desligamento da máquina e } \\
\text { desmontagem de componentes, operação complexa e } \\
\text { demorada. }\end{array}$ \\
\hline Direção & $\begin{array}{l}\text { A rabiça do motocultivador é elemento de } \\
\text { direcionamento da máquina mas não atua de forma } \\
\text { isolada. A condução e desvio de obstáculos com a } \\
\text { máquina exige esforço proporcional à tração deste com } \\
\text { o piso. Há situações onde o indivíduo, mesmo que } \\
\text { aplique todo sua força, não consegue fazer curvas sem a } \\
\text { utilização da embreagem. Esta retira a tração da(s) } \\
\text { roda(s) permitindo que o operador movimente as rabiças } \\
\text { e redirecione a máquina. }\end{array}$ \\
\hline
\end{tabular}

O quadro a seguir apresenta os resultados quantitativos do método Usa-Design para o motocultivador. 


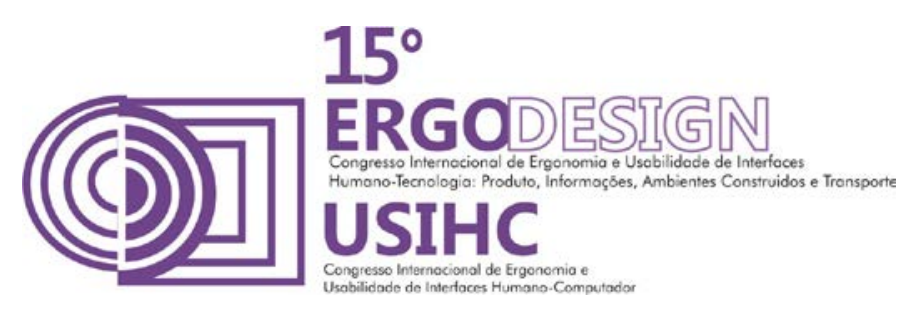

Quadro 8. Resumo das avaliações pela ISO 9241-11 (1998) e os princípios de Jordan (1998) utilizando o modelo U-D@ (MERINO et al., 2012).

\begin{tabular}{|l|c|}
\hline \multicolumn{1}{|c|}{ Item } & Motocultivador \\
\hline Eficiência & Atende \\
\hline Eficácia & Atende Parcialmente \\
\hline Satisfação & Atende \\
\hline Consistência & Não atende \\
\hline Compatibilidade & Não Atende \\
\hline Capacidade & Não Atende \\
\hline Retro-Alimentação & Não Atende \\
\hline Prevenção de erro & Não Atende \\
\hline Controle do usuário & Não Atende \\
\hline Clareza visual & Atende Parcialmente \\
\hline Priorização da funcionalidade & Não Atende \\
\hline Transferência de tecnologia & Atende Parcialmente \\
\hline Evidência & Atende Parcialmente \\
\hline
\end{tabular}

O resultado da avaliação de usabilidade em termos de ISO 9241-11 (1998) apresentada na fase II apontou como ponto fraco do motocultivador a sua eficácia. Isso pode ser justificado pela baixa velocidade na execução das operações agrícolas em decorrência de sua pequena dimensão e potência, contribui para isso o fato de possuir apenas duas rodas.

Pelo ponto de vista dos dez princípios de Jordan (1998) o motocultivador não atendeu a 7 destes.

Os princípios de pior nota foram a priorização da funcionalidade e prevenção de erros. Isto pode ser explicado pela ausência de informações de "como executar" determinada operação ou se esta "foi ou não executada". Existe ainda, no setor de máquinas agrícolas de pequeno porte, uma resistência a novas tecnologias que poderiam melhorar a interação com 0 usuário, a exemplo da eletrônica. A robustez e durabilidade são fatores preponderantes na escolha da máquina, assim aspectos ergonômicos são secundários no momento da escolha da máquina. Exemplo disso é que o motocultivador não possui painel de instrumentos, sequer consta na lista de opcionais.

\section{CONCLUSÕES}

O estado de Santa Catarina possui uma das maiores relações de pequenos tratores sobre a frota total. Considerável porcentagem dessas máquinas é do tipo motocultivador. Constatações recentes sobre o elevado índice de acidentes com essa máquina induz a investigação das causas desses acidentes. A pequena facilidade de uso, apontada neste estudo, pode representar uma das causas.

O emprego do modelo U-DC se mostrou apropriado para análise de produto da área agrícola explorando com profundidade o tema. Já o questionário possibilitou, de forma rápida, a obtenção da impressão do usuário sobre a máquina.

Os resultados, tanto pela avaliação utilizando o modelo U-D® (MERINO et al., 2012) como no questionário demonstraram a fragilidade do projeto do motocultivador, evidenciando a necessidade de melhorias nos aspectos funcionais e de segurança.

A pesquisa aponta questões importantes à Ergonomia que constituem contribuições no campo social: com a possibilidade de redução do número de mortos e feridos no trabalho 


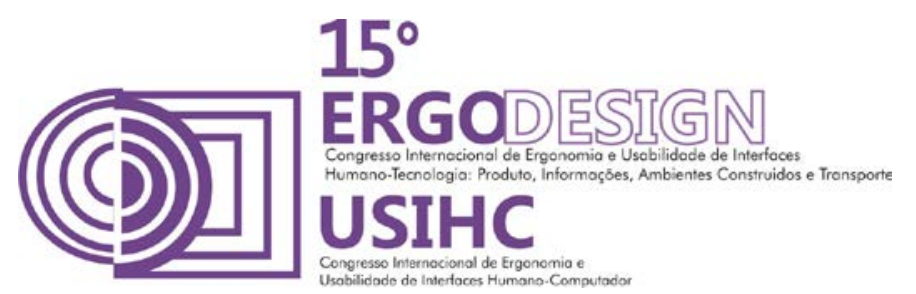

agrícola; econômica: pela possibilidade de redução dos custos de afastamentos e indenizações trabalhistas; bem como tecnológicas: por oportunizar melhorias em projetos de produtos agrícolas.

Sugere-se, para trabalhos futuros, a comparação da usabilidade de um trator agrícola com o motocultivador a fim de expor o distanciamento entre os projetos das duas máquinas que se destinam à operações agrícolas similares.

\section{REFERÊNCIAS BIBLIOGRÁFICAS}

BRAY. Francesca. The Rice Economies. Oxford: Blackwel, 1986.

GIL, A. C. Como elaborar projetos de pesquisa. 4. ed. São Paulo: Atlas, 2002.

IBGE. Censo Agropecuário 2006: Resultado Preliminar. Rio de Janeiro: IBGE, 2007, 141 p.

ISO (1998). ISO 9241-11: Ergonomic requirements for office work with visual display terminals (VDTs). Part 11 Guidelines for specifying and measuring usability. Gènève: International Organisation for Standardisation.

JORDAN, P.W. An Introduction to Usability. Lodon: Taylor \& Francis.1998.

MÁRQUEZ, Luiz. Tractores Agrícolas: Tecnología y Utilización. Editora B\&H. Madrid, 2011.

MERINO, Giselle Schmidt Alves Díaz et al. Usability in Product Design - The importance and need for systemic assessment models in product development - Usa-Design Model (U-D). Work, Usa, v. 41, n. 1, p.1045-1052, fev. 2012.

MITARAI, Masafumi ; SICAT, Julius Caesar V. ; KINOSHITA, Osamu ; TOYOMITSU, Yukio. Survey of Walking Tractor Operating Comfort in Nueva Ecija, Philippines. Japanese Journal of Farm Work Research, 2008, Vol. 43(2), p.59-66.

ODORIZZI, W.; MASIERO, F.C.; VEIGA, R.K. Acidentes com máquinas agrícolas: pesquisa realizada com alunos do IFC Câmpus Rio do Sul. In: VI MICTI. Anais... ISSN 2316-7165. Outubro de 2013.

SAM, Bini ; KATHIRVEL, K. Development and evaluation of vibration isolators for reducing hand transmitted vibration of walking and riding type power tillers. Biosystems Engineering, 2009, Vol.103 (4), p. 427-437.

VEIGA, R. K. ; GONTIJO, L. A. ; MASIERO, F. C. ; ODORIZZI, W. ; VENTURI, J. . Análise Ergonômica do Trabalho de Operador de Motocultivador em Instituição de Ensino de Santa Catarina. In: $14^{\circ}$ Congresso Internacional de Ergonomia e Usabilidade de Interfaces Humano-Tecnologia: Produto, Informações, Ambiente Construído e Transporte, 2014, Joinville, SC. Anais do $14^{\circ}$ ERGODESIGN/USIHC. Joinville, SC: Univille, 2014a. v. 1. p. 1-14.

VEIGA, R. K. ; GONTIJO, L. A. ; MASIERO, F. C. ; VENTURI, J. ; ODORIZZI, W.. Emprego da análise ergonômica do trabalho em atividade com máquina agrícola motorizada. Exacta - EP, São Paulo, v. 12, n. 1, p. 123-123, 2014b.

VEIGA, R. K. ; MASIERO, F. C.; GONTIJO, L. A.; ODORIZZI, W.. Multitarefas. Cultivar Máquinas, V.12, n.142, p.6-9, 2014c.

VENTURI, J. ; VEIGA, R. K. ; GONTIJO, L. A. ; MASIERO, F. C. ; ODORIZZI, W.. Utilização do software Surfer ${ }^{\circledR} 8.0$ para a análise da distribuição de ruído em máquinas agrícolas. In: Anais do XXXIV Encontro Nacional de Engenharia de Produção, 2014d, Curitiba, PR. ENEGEP 2014.

VIEIRA, S. Como escrever uma tese. 6 ed. São Paulo: Editora Atlas, 2008. 